\title{
MULTI-OBJECTIVE OPTIMIZATION OF GREENHOUSE GAS EMISSIONS IN HIGHWAY CONSTRUCTION PROJECTS
}

\author{
Gulbin Ozcan-Deniz ${ }^{1}$ and Yimin $\mathrm{Zhu}^{2}$
}

\begin{abstract}
With the increasing interest in relationships between built environments and ecosystems, the environmental impacts of the construction industry have been a subject of many studies. Based on the results of previous studies using construction systems modeling and life cycle assessment, the authors treated greenhouse gas (GHG) emissions as an additional project objective to time and cost, and applied multi-objective optimization to derive optimal solutions for transportation projects. Two highway construction case studies were analyzed for relationships between time, cost and environmental impacts. The results showed strong positive correlation between time and cost, moderate positive correlation between cost and GHG emissions, and weak positive correlation between time and GHG emissions. The results suggest that it is less likely that time and GHG emissions may affect each other. It is more so to time and GHG emissions. In addition, it is unlikely that there are common factors that can simultaneously affect cost and GHG emissions, or time and GHG emissions. Future studies are needed to include other types of environmental impacts and further understand the advantages and disadvantages of the lack of dependency between time and GHG emissions, as well as cost and GHG emissions in order to enhance sustainable construction.
\end{abstract}

\footnotetext{
${ }^{1}$ Assistant Professor, College of Architecture and the Built Environment, Philadelphia University, Philadelphia, PA, 19144, USA, Email: denizg@philau.edu

${ }^{2}$ Professor, Louisiana State University, Department of Construction Management, Baton Rouge, LA 70803, USA, Email: yiminzhu@1su.edu
} 
Keywords: Multi-objective optimization, environmental impact, greenhouse gas emissions, highway construction, time, cost

\section{Introduction}

The construction sector plays a significant role in the increase of environmental impacts nationally and globally. In the U.S., buildings were accounted for $39 \%$ of primary energy use, $40 \%$ of raw material use, and $38 \%$ of $\mathrm{CO}_{2}$ emissions (USGBC, 2008). EPA reported that $1.7 \%$ of total U.S. greenhouse gas (GHG) emissions and $6 \%$ of total industrial-related emissions in the U.S. were produced by the construction industry, which placed this industry to the list of top emitting sectors (EPA, 2009). According to previous research, the construction sector ranked the third in producing GHG emissions, following the oil/gas and chemical industries (Truitt, 2009). Additionally, $13.4 \%$ of the total industrial GHG emissions in the U.S. were produced by highway, street, and bridge construction (Kibert, 2002). Regarding raw material use, the U.S. Geological Survey (USGS) reported that 1.5 billion metric tons (Gt) of natural aggregates, 48 million metric tons (Mt) of concrete, $35 \mathrm{Mt}$ of asphalt, and $6 \mathrm{Mt}$ of steel were used by interstate highway construction in total. The estimates were based on a 42,500-mile $(73,000-\mathrm{km})$ interstate highway system with four 12-foot (3.7-m) wide lanes (USGS, 2006). Due to such a considerable amount of environmental impacts, increasing interest has been paid to highway construction projects in adopting sustainability practice such as the application of green rating systems.

Over the past years, literature on sustainability has focused on defining and assessing environmental performance indicators and environmental scoring systems (e.g. Yao, Shen, \& Yam, 2007). The significant contribution of the construction industry to GHG emissions has triggered extensive research attention for environmental impact mitigation technologies in both 
building and highway construction. For example, systems thinking, life cycle thinking, and integrated design process (USGBC, 2012) were adopted in sustainable construction. The Leadership in Environmental and Energy Design (LEED) was introduced by the U.S. Green Building Council (USGBC) to assess buildings in terms of environmental performance. Meanwhile, the Department of Transportation (DOT) in various states also implemented sustainable practices such as reusing materials at the site (Gambatese, 2005). In addition, assessment methods of environmental performance of highway construction have also been developed. For example, the New York State DOT introduced GreenLITES to measure sustainability performance of highway projects. Only recently, the Envision rating was introduced by the Institute for Sustainable Infrastructure (ISI) as a national scoring tool for highway projects. Envision is a green rating system to assess the sustainability of all types and sizes of infrastructure projects including roads and bridges. It has 60 credit points in five main categories, Quality of Life, Leadership, Resource Allocation, Natural World, and Climate and Risk (ISI, 2016).

Even though the concept of sustainable construction is not new in both building and highway projects, improving the application of environmentally conscious construction in a timely and feasible manner to construction projects is still in its early stage. Principles of sustainable infrastructure have evolved with the advancement in designs, materials, and construction technologies. Increasing interest in effectively reducing environmental impacts, highway construction practitioners led to the search for delivering projects in a resourceefficient, cost-effective, and environmentally friendly manner (Jha, Shariat, Abdullah, \& Devkota, 2012). As an example, Carpenter (2007) quantified cost and environmental impact benefits of highway projects by using a life cycle assessment (LCA) approach. 
Environmentally conscious construction was defined as the encouragement of ecological, economic, and social-cultural sustainability in buildings (Kua \& Lee, 2002). Therefore, the concept includes environmental as well as other objectives. Although previous researchers clearly summarized the significance of environmental impacts during the construction phase (e.g. Bilec, Ries, Matthews, \& Sharrard, 2006), there are still gaps between the ultimate goal of environmentally conscious construction and contributions of those studies. This is mainly because most of the studies have been directed to understanding and analyzing solely the relationship between environmental impacts and construction processes, and have overlooked the multi-objective nature of construction projects, even though there are a couple of exceptions (e.g. Marzouk, Madany, Abou-Zied, \& El-Said, 2008).

In this study, time, cost and environmental impact (TCEI) objectives are analyzed to understand the interdependency between them. There are external factors in the construction system, which produce an impact on the relationship between TCEI. They are referred to as project conditions in this study, and affect the flow of construction projects through its life cycle by influencing the selection of construction methods. The details regarding this process have been covered in previous publications (Ozcan-Deniz \& Zhu, 2016). Using the construction method selection mechanism in the previous study, this paper will focus on the correlation between TCEI. Being an effective tool in optimizing multiple parameters, multi-objective optimization is used in this study to optimize these three potentially conflicting objectives in construction projects. Two highway construction cases are used in this study. The first part of this paper contains background information about LCA, highway construction, and multiobjective optimization. Second part is focused on the details of the multi-objective optimization 
process. Then, the relationship between time, cost and environmental impacts is discussed using the two cases. Finally, conclusions and future directions regarding this study are summarized.

\section{Background}

\subsection{Life Cycle Assessment (LCA)}

LCA was considered as an important tool to analyze and calculate resource consumption and environmental impacts of products and services from a "cradle-to-grave" perspective (Bengtsson, 2001). The life cycle of building was divided into four stages as raw material extraction, manufacturing, use, and end-of-life (Bilec, Ries, Matthews, \& Sharrard, 2006). Construction literature is rich in LCA studies focusing on especially greenhouse gas (GHG) emissions, energy consumption, and sustainable resource utilization. For example, Varun et al. (2012) performed LCA to find out the energy consumption and GHG emissions of an example building. Sartori \& Hestnes (2007) used LCA to compare the energy utilization of conventional and low-energy buildings through their lives, and showed a linear relationship between the operating and total energy demand of these buildings. To enhance the integration of sustainability and construction operations, Li, Zhu, \& Zhang (2010) proposed a work breakdown structure to identify materials and equipment used in a construction activity, and LCA was applied to the materials and equipment for environmental analysis. In the scope of this study, the calculation of environmental impacts is only focused on evaluating GHG emissions by using the LCA approach.

\subsection{Highway Resurfacing Construction Methods}


Highway resurfacing projects consist of core activities such as milling existing asphalt, placing asphaltic concrete, and putting the concrete friction course. A typical resurfacing operation is often performed lane by lane. Normally, existing asphalt is first milled and hauled away by dump trucks to be recycled. Then virgin or recycled asphaltic concrete is placed. An asphalt composition can be different in terms of recycled concrete amount and its temperature of mixing, which results in different environmental performance.

There are research studies analyzing different ways to perform resurfacing of roads. Uhlman (2009) compared eco-efficiency of chip seal resurfacing, hot mix asphalt (HMA) overlays, and micro-surfacing as being alternative types of resurfacing operations. Hot chip seal resurfacing was reported to have higher global warming potential compared to colder substitutes. Similarly, Chehovits \& Galehouse (2010) compared energy usage and GHG emissions of resurfacing operations. They analyzed HMA, Hot-in-place (HIP) recycling, chip seal resurfacing, and micro-surfacing in their list of pavement preservation treatments. The results showed that different types of resurfacing operations required differing amounts of energy per year of pavement life.

Fuel selection, equipment idling, electricity use, equipment maintenance, equipment selection, and materials recycling were also reported to affect GHG emissions (EPA, 2009). Material recycling techniques such as using Reclaimed Asphalt Pavement "RAP" reduced demand for new materials, saved energy, and reduced carbon output (Huddleston, 2008). Warm mix asphalt (WMA) was another technique decreasing fuel/energy consumption, GHG emissions, and dust production (Chowdhury \& Button, 2008). Overall, WMA provided 15\% reduction on the environment impacts of HMA (Hassan, 2009). As an emerging technology, HIP recycling also significantly reduced overall energy and resource use (CCE, 2005). When HMA 
and HIP technologies were compared, HIP consumed less energy than HMA (Terrel \& Hicks, 2008).

In the scope of this study, existing methods and new technologies for highway construction were used to generate several construction alternatives for resurfacing projects. Possible construction methods were defined for core activities, i.e., milling, resurfacing, and placing friction course. Various construction methods in terms of material, equipment and technology selection were considered for the three activities so that their TCEI values were calculated and analyzed.

\subsection{Applications of Multi-Objective Optimization in Construction}

Existing construction literature is rich in studies that concentrate on optimizing multiple project objectives. Traditionally, two most common objectives to be optimized simultaneously are time and cost of construction. In recent years, quality or environmental concerns are often incorporated as another dimension in optimization. The results of optimization are a set of nondominant solutions that satisfy a set of objectives for optimization. Researchers can then use the results to determine if there exists any relationship between variables involved in the optimization problem.

According to Zheng, Ng, \& Kumaraswamy (2005), time-cost trade-off and resource allocation should be analyzed related to each other for a successful project planning and scheduling. Feng, Liu, \& Burns (1997) viewed time-cost trade-off problem and investigated the effects of resource selection such as crew sizes, equipment, method, and technologies on this relation. Marzouk \& Moselhi (2004) presented a framework for optimizing earthmoving 
operations, and considered the availability and characteristics of earthmoving equipment and their cost components together with time-cost trade-off analysis.

In addition to time-cost trade-off studies, many researchers used multi-scale optimization to analyze multiple project objectives. El-Rayes \& Kandil (2005) evaluated the impact of various resource utilization plans on project performance to find an optimal/near optimal solution by optimizing time, cost, and quality. Whereas, Tronchin et al. (2015) created a multi-scale methodology to analyze economics, comfort, environmental impact and durability. In a similar study, Griego et al. (2015) used optimization analysis to find out the most cost-effective potential for energy conservation in both new and existing offices.

Optimization of project environmental performance is a developing concept in construction and it has recently been handled together with time and cost objectives. For example, Marzouk et al. (2008) performed a similar study by optimizing total pollution with project duration and cost by using genetic algorithms (GAs). Although the previous studies were successful in optimizing environmental performance general, still a specific study on GHG with time and cost objectives is missing. This research tries to fulfill this gap by concentrating on TCEI optimization in highway projects.

\section{Methodology}

The flowchart in Figure 1 shows a high-level process of the steps involved in this study. 


\section{Figure 1 TCEI Optimization Flowchart}

\subsection{Activity Definition}

A resurfacing construction project can be defined as a set of activities and their construction operations to perform these activities. In reality, there are not many different types of activities involved in resurfacing projects. Mainly, there are three types of activities, milling existing asphalt, placing asphaltic concrete, and putting the friction course. Each activity, on the other hand, can be defined by construction operations, which are further defined by three indicators, materials, equipment, and stabilizing additives used to perform each activity.

\subsection{Alternatives of Construction Operations}

Resurfacing construction operations may have different alternatives due to the use of different materials, equipment, or stabilizing additives. Consequently, each activity, as well as its alternatives, has specific time, cost and GHG emissions.

There are many designs of asphalt mix. Marshall and Hveem are the two widely accepted HMA design methods (Bahia, 1993). In addition to these, the Strategic Highway Research 
Program (SHRP) developed a new asphalt type called Superpave, an acronym for superior performing asphalt pavements (Larsen, 2003). Another mix method, WMA technology was developed to perform the mixing process in a lower temperature than HMA (Chowdhury \& Button, 2008).

The equipment technology has also evolved for better performance of milling and placing asphalt. HIP recycling technology combined milling existing asphalt and placing asphaltic concrete activities in resurfacing projects. By this was, only a single unit is utilized for both recycling existing pavement and mixing milled pavement with new paving materials, while eliminating hauling and handling of the recycled HMA from milling (Russell, Uhlmeyer, DeVol, \& Johnson, 2010).

The selection of equipment was based on not only the technology, but also fuel type and use. Low-carbon or biofuels, which were mostly derived by soybeans, were promising strategies to reduce life cycle GHG emissions (EPA, 2009). Additionally, mixing additives in friction course need to be checked to prevent undesirable environmental side effects (Bushman et al. 2004). Stabilizing additives have two different alternatives as used by the Florida Department of Transportation (FDOT). Two possible stabilizing additive alternatives are FC-5 and FC-9.5. They have different design requirements and use either a mineral or a cellulose fiber-stabilizing additive.

\subsection{Possible Combinations for Alternatives}

With considerations of various construction technologies discussed in literature or applied in practice, construction operation alternatives to be analyzed in this study include virgin and recycled HMA with conventional or biodiesel equipment, virgin WMA with conventional 
equipment, Superpave, and HIP mix (Marshall + milled asphalt) with conventional or biodiesel HIP equipment. These considerations lead to different combinations of operations as shown in Table 1.

Table 1 Construction Methods for Resurfacing Project Activities

These combinations represent different ways, or alternatives, to execute a resurfacing construction project. As each different construction operation uses different material, equipment, and stabilizing additive; and each alternative ends up having a different TCEI value. An example TCEI value is defined as $\left(T^{\circ}, C^{\circ}, E I^{\circ}\right)$ for a construction operation alternative. Time $T^{\circ}$ is calculated as the project duration. Cost $C^{\circ}$ is the total cost of all activities of the solution. Environmental impact $E I^{\circ}$ is the total environmental impact, which refers to the total GHG emissions of all activities of a construction operation plan. The estimated time, cost, and GHG values are used for multi-objective optimization.

\subsection{Data Preparation}

Project duration, project cost and environmental impact data were collected or estimated based on data collected from plans, contracts (which includes resource types and amount as well as fuel consumptions of equipment), schedules, and daily progress reports of resurfacing construction projects performed by the FDOT. The process of data preparation included four basic steps:

1) Project decomposition

A resurfacing project was modeled using three types of activities and their alternatives of construction operations.

2) Schedule calculation 
Project durations were derived using conventional scheduling methods. Project schedules were supplied by the FDOT so that the duration of three activities actually executed could be identified. For alternatives of construction operations, activity durations were calculated based on productivity values. The productivity values were obtained by using either RS Means database or reports from the FL State Material Office. The productivity values were given in terms of daily output per unit of work done. The total amount of work was divided by the daily output values to calculate the duration of each activity.

3) Cost calculation

Project cost data was derived using conventional estimating methods. Costs of three activities that were actually executed were given in the quantity estimation sheets of projects. The contract from FDOT included unit costs and quantities of resources. The unit costs and quantities of work done for three activities were multiplied for calculating the cost. The unit costs in the contract were used for calculating the cost of the original construction operation. For the alternative construction methods, the unit costs of different materials were obtained from literature sources. Another way to estimate the unit cost was to find the proportion between the unit costs of the alternative and the original material. The costs for all alternatives were estimated by using both ways.

4) Environmental Impact (EI) calculation

Although EI was limited to GHG emissions in this study, GHG emission calculations were much more detailed than project durations and costs. This was mainly caused by the lack of proper and feasible LCA software for highway construction operations. GHG emission calculation methods using LCA are available in literature, including using LCA software (e.g. ATHENA Impact Estimator for Buildings or BEES for buildings), the life 
cycle inventory (LCI) databases (e.g., the one developed by the National Renewable Energy Laboratory NREL (2004)), and literature sources.

Even though a number of LCA software is available for building construction, ATHENA Impact Estimator for Highways is the only one that released recently for infrastructure sustainability calculations. ATHENA Impact Estimator for Highways allows users to benefit from a library 50 designs and compare alternative design options (ATHENA, 2016). As it only allows creating projects in nine regional locations from Vancouver to Nova Scotia in Canada (no U.S. locations), ATHENA Impact Estimator for Highways has not been used in this study. Instead, data from literature sources have been selected to calculate GHG emissions for the scope of this paper.

Among various literature sources, EI of different types of fuel was provided in the EPA database (EPA, 2009). Similarly, the EPA MOBILE 6.1/6.2 estimated several types of pollutants, such as carbon dioxide $\left(\mathrm{CO}_{2}\right)$, hydrocarbons $(\mathrm{HC})$, carbon monoxide $(\mathrm{CO})$, and oxides of nitrogen (NOx), generated by gas, diesel, or natural-gas-fueled cars, trucks, buses, or motorcycles (EPA, 2003).

The LCA system boundary used in this study is shown in Figure 2. The quantity take-off data were analyzed with process, transportation and landfill inventory data to calculate the GHG (kg CO2 eq) of different materials. On the other hand, fuel consumption data in gallons for gasoline and diesel equipment were utilized to determine the GHG caused by equipment. This information needed to be converted to $\mathrm{kg} \mathrm{CO} 2$ eq to obtain the total $\mathrm{GHG}$ emissions for materials and equipment of the project. The first step was to find out the types and quantities of gases released to air by the consumption of gasoline or diesel fuel sources. EPA (2009) developed an LCI that included gas releases of different energy sources. The types of gas 
releases for gasoline and diesel equipment are shown in Table 2 and Table 3 respectively. By converting the fuel consumption of equipment from gallons to liters and using the gas release information from EPA in $\mathrm{kg} / \mathrm{L}$, the quantities of gases released were calculated in kilogram $(\mathrm{kg})$.

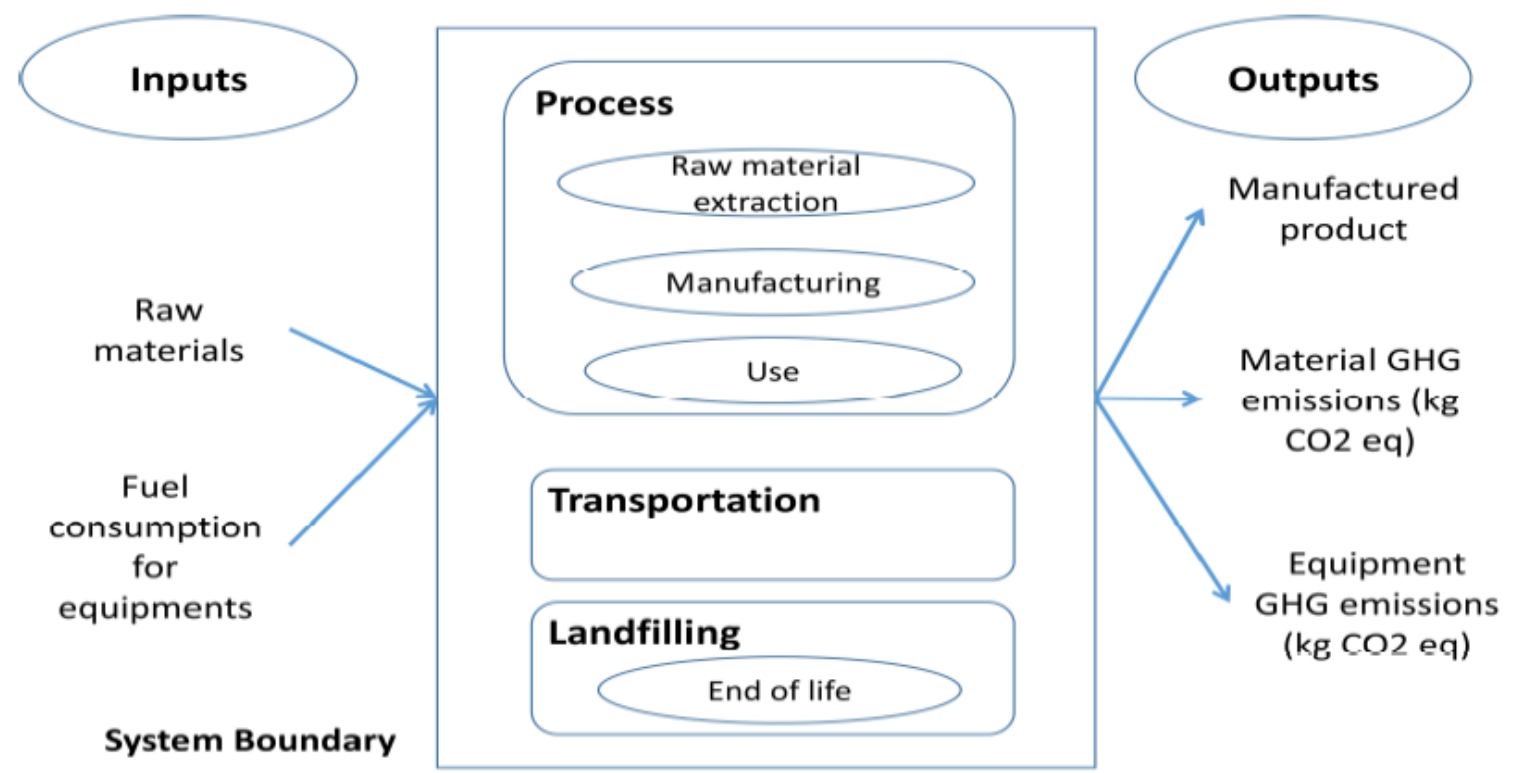

Figure 2 The LCA System Boundary

Table 2 Gas Releases for Gasoline Equipment (source: EPA single truck)

Table 3 Gas Releases for Diesel Equipment (source: EPA single truck)

The second step was to convert gas releases to the equivalent $\mathrm{kg} \mathrm{CO}$. The gases that contribute GHG emissions and their percentage weights are shown in Table 4 as given in a study by Stern et al. (2006). It can be observed that some of the gases released by fuel consumption do not contribute to GHG such as nitrogen oxides (NOx) and sulfur oxides (SOx). Therefore, only 
the gases that contribute to GHG emissions were used in the calculation. Finally, the GHG emissions of materials and equipment were summed up to obtain the total GHG (kg CO2 eq) emissions of the construction method alternatives.

\section{Table 4 Weights of Gases for GHG Content}

\subsection{Performing Multi-Objective Optimization}

As highway resurfacing projects include only three activities, there is a limited amount of possible construction operation alternatives. The multi-objective optimization procedure is designed based on the multi-objective optimization literature possible construction operation alternatives, to look for the relationship between TCEI. The optimization analysis procedure is as follows:

1. Generate a population of solutions randomly.

2. Determine the fitness for each solution on the population.

3. Perform crossover and mutation.

4. Generate a new generation.

5. Check for convergence of solutions, if level of accuracy is adequate, then stop.

6. Repeat from step 2 as necessary.

\section{Random Population Generation}

A construction project is defined by a set of changing project conditions that in turn determine the selection of a particular associated construction method. The change in project conditions is defined by a set of probability of occurrences of $n$ conditions. "i" denotes the $\mathrm{i}^{\text {th }}$ condition, which has a number of different probability values $\mathrm{L}_{\mathrm{i}}$. There are up to $U=$ 
$\Pi \quad L i$ different inputs of project conditions, where $U$ is the universe of possible solutions. Thus, the size of the solution universe $U$ is equal to $L_{1} x L_{2} x \ldots x L_{n}$.

A solution, represented by a chromosome, such as solution $m$ (Figure 3), contains all conditions of a project, so the length of a chromosome is $n$. Each condition, as well as its probabilities $\left(\mathrm{P}_{\mathrm{i}}\right)$, are analyzed separately and have an associated value of time, cost and environmental impact.

Solution $m$

\begin{tabular}{|l|l|l|l|l|}
\hline $\mathrm{P}_{1}$ & $\mathrm{P}_{2}$ & $\mathrm{P}_{3}$ & $\cdots$ & $\mathrm{P}_{\mathrm{n}}$ \\
\hline
\end{tabular}

\section{Figure 3 An Example Chromosome for Solution $m$}

After the construction method is selected, a solution, $S_{\mathrm{m}}$, is thus associated with three values, time, cost and environmental impact, defined as $\left(\mathrm{T}_{\mathrm{m}}, \mathrm{C}_{\mathrm{m}}, \mathrm{EI}_{\mathrm{m}}\right)$. Time $\mathrm{T}_{\mathrm{m}}$ is calculated as the project duration. Cost $\mathrm{C}_{\mathrm{m}}$ is the total cost of all activities of the solution. Environmental impact $\mathrm{EI}_{\mathrm{m}}$ is the total environmental impact, which refers to the total $\mathrm{GHG}$ emissions of all activities of the solution. The estimated time, cost and GHG values for different probability inputs form different population of solutions, which are used for the multi-objective optimization. Once the universe of possible solutions is obtained, random populations of solutions are generated by using different probability inputs and their associated TCEI values.

\section{Objective Function and Fitness Evaluation}

The multi-objective optimization process searches for optimal/near optimal tradeoffs among minimizing project duration, project cost and project GHG. The objective functions (OFs) 
for time, cost and EI are expressed as in Equation 1 in a broader sense. As the most feasible project is expected to have a minimum time, cost and EI combination, the objective function is set to have minimum of these values among all possible solutions.

$\mathrm{OF}_{\mathrm{T}}=\mathrm{MIN}\left(\mathrm{T}_{\mathrm{m}}, \mathrm{C}_{\mathrm{m}}, \mathrm{EI}_{\mathrm{m}}\right)$, where $\mathrm{m}=[1, \mathrm{U}] \quad$ Equation 1

The multivariate approach is defined by a Euclidian space with three dimensions as T, C, and EI. Different solutions of TCEI objectives are expected to lie in a certain boundary called the possibility frontier. The possibility frontier in the space created with the lowest boundary being the corner of the box created by the boundaries that is closer to the origin $(0,0,0)$. The corner point is calculated by selecting the minimum time, cost and environmental impact achievable in each activity and adding them accordingly to obtain the total minimum achievable.

This point is considered as the origin of a new subspace containing all possible existing solutions only. An important point is that the dimensions of project objectives (TCEI) are different from each other. The estimated time, cost, and EI (i.e. GHG) are days, dollars (\$), $\mathrm{kg}$ $\mathrm{CO} 2$ eq respectively and thus, they need to be normalized before the optimization. The new space of possible solutions is normalized using as an upper limit of the corresponding maximums of time, cost and environmental impact. The total difference between the maximum and the minimum on each dimension will have then a total dimension of one. The normalized values for time, cost and environmental impact for a solution $\mathrm{K}$ are calculated by using Equation 2, Equation 3, and Equation 4. The objective function utilizes the normalized values of the project objectives to find the optimal TCEI and its corresponding construction methods.

Equation 2

Equation 3 
Equation 4

The fitness function in Equation 5 is used to evaluate the performance of each solution in a more detailed manner than Equation 1 by using normalized T, C, and EI values. As mentioned before the purpose is to have minimum $\mathrm{T}, \mathrm{C}$, and $\mathrm{EI}$ values for a feasible project. The performance is defined as the total distance between the solution and the origin in the new normalized subspace. A lower fitness value means a better solution as the solution is closer to the origin. The solutions with the minimum fitness value are placed in the optimal solution set.

Equation 5

\section{Selection of Solutions}

At this stage, a stopping criterion is implemented to set the desirable convergence rate. As time, cost and environmental impact values should be as close to the origin $(0,0,0)$ as possible, but cannot possibly have zero values, the minimum possible values of TCEI is used as the stopping criteria. The best possible answer is obtained by selecting the chromosomes considering the sorted fitness values of the population. When the chromosomes in the resulting population comply with the criteria set in size and proximity (i.e. in terms of TCEI values and the distance of these values to the origin), the most feasible solution is achieved, and the optimization process is finalized. An application example will be analyzed in the Case Studies part to illustrate the use of the procedure.

\section{TCEI Interdependency}


Simple linear correlation, i.e. Pearson correlation, was used to determine the extent of relationship between the three project objectives. Two variables are compared at one time and the value of correlation tells if the variables are proportional. The Pearson's correlation coefficient is calculated by using three different sums of squares (SS). As there are three variables (time, cost, and EI) in this study, there are three sets of SS calculation in pairs (time and cost, time and EI, and cost and EI). The details of these equations can be found in (OzcanDeniz, 2011). As an example, the SS equations for time and EI are shown in Equation 6, Equation 7, and Equation 8. These equations were further used to determine the correlation coefficient (r), which is shown in Equation 9.

Equation 6

Equation 7

Equation 8

Equation 9

The correlation coefficient (r) is a measure of linear correlation between two variables. It gives a value between +1 and -1 , where 1 is total positive correlation, 0 is no correlation, and -1 is negative correlation. Additionally, the coefficient of determination $\left(\mathrm{r}^{2}\right)$ shows how well the data fits on a line or curve. It represents the proportion of common variation in the two variables.

\section{Case Studies and TCEI Interdependencies}


Two case studies were used in this study with three activities. According to the original construction operation, milling was performed with conventional equipment, and milled asphalt was hauled by dump trucks to be recycled. Superpave asphalt was used in paving, while FC-5 was used for the friction course layer. In addition to the original construction method, other existing methods and new technologies for resurfacing construction were used to generate several construction operation alternatives for each project. The differences among alternatives were reflected by using different types of materials, equipment, and stabilizing additives of materials. The various options considered for the resurfacing construction projects are presented in Table 1. There are several resurfacing, milling and friction course methods available to allow the selection of different construction operation alternatives. Time, cost and GHG were calculated for different types of construction operations by using the procedures explained before in the data preparation section.

After time, cost, and GHG values were calculated for different construction operation alternatives, a random population was selected from time, cost and GHG values to start TCEI optimization discussed in the methodology part. A random population of solutions from each case study is generated by using the RANDBETWEEN function in MS Excel. The RANDBETWEEN function was used to select a random population out of the limited construction methods available. The random populations for Case Study 1 and 2 are shown in Table 5 and Table 6 , respectively. The random populations were used to define the associated construction methods used to deliver the project. Then, TCEI values were calculated for the chromosomes of the random population, as solutions were associated with their duration, cost and GHG. As an example, Trial\#1 represents a project option with 36 days duration, 
$\$ 1,945,751.89$ of cost, and 3,857,983.11 kg CO2 GHG emissions. Equation 2, Equation 3, and Equation 4 were used to calculate the normalized values of time, cost and GHG emissions.

Table 5 A Random Population of TCEI Results from Case Study 1

Table 6 A Random Population of TCEI Results from Case Study 2

The fitness function, which was given in Equation 5, was used to calculate distance to the origin and evaluate the performance of each solution. Table 7 shows the fitness function values together with the normalized TCEI for Case Study 1 . As the origin has $(0,0,0)$ values for TCEI, the solution or solutions with the lowest fitness function have the least distance to the origin. In this case, Trials 11,12 , and 20 have the lowest fitness function value as 0.33 .

Table 7 Fitness Function Values and Normalized TCEI (Case Study 1)

The normalized values were used in accordance with minimizing the time, cost and GHG objectives. The subspace of TCEI was created for all possible existing solutions. As an example, the TCEI of five solutions drown on the new space. The 2-D figures of Cost vs EI, Cost vs Time are shown in Figure 4. The numbers in the figures refer to the trial numbers. As some of the trials ended up having minimum EI (e.g., Trial 4), minimum cost and minimum time (e.g., Trial 11) values, the results of these trials are drown on the axis, where the normalized value is zero. 


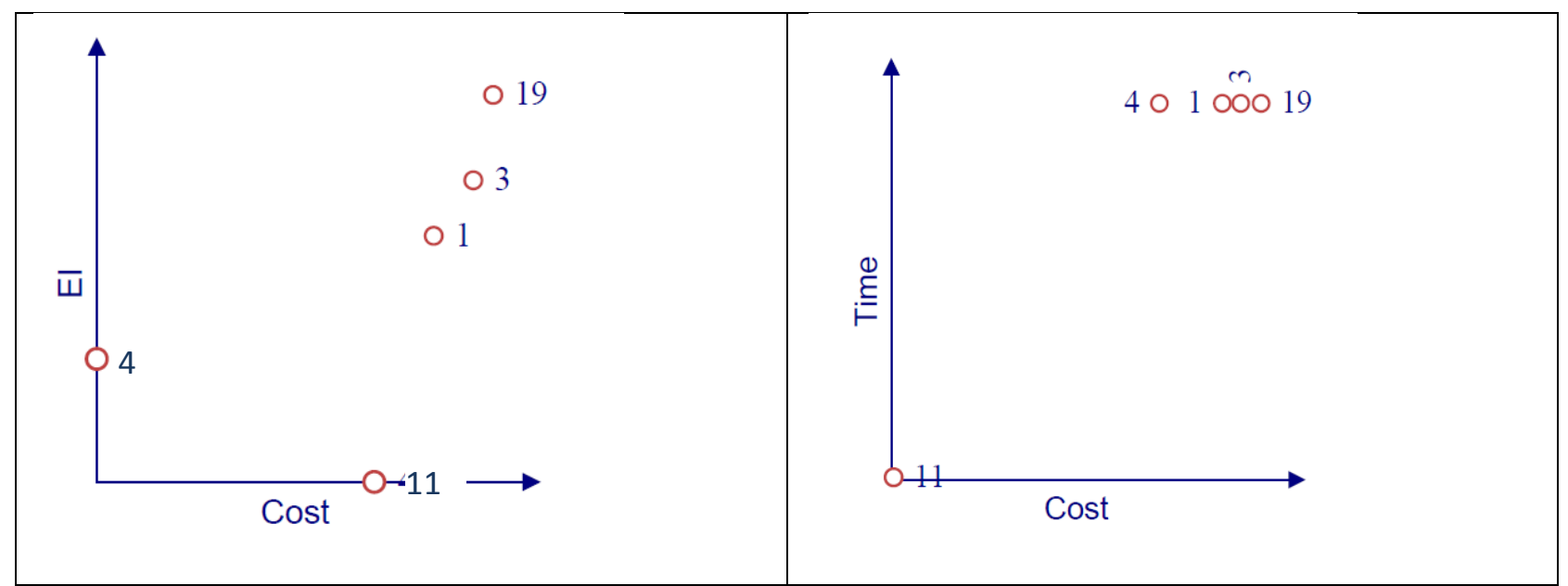

Figure 4 2-D Figures of Cost vs EI, Cost vs Time

As mentioned before, the nature of the highway construction projects limits the number of available construction methods. Consequently, the TCEI values calculated based on construction methods are bounded between certain values. As the population of solutions is limited, the results of optimization have been obtained without requiring the generation of further populations as in common genetic algorithm procedure. The full genetic algorithm procedure was not needed to optimize with a limited population. The procedure was given to emphasize that the framework can be applied to projects other than highway construction. However, with a random population of 20 solutions, different probability ranges were covered, and the results converged to the optimum minimum points of TCEI with the initial population because of the nature of highway projects.

The results of the multi-objective selection showed that Trials 11, 12, and 20 have the lowest fitness function. All results had the same construction method and demonstrated that using HIP mix with biodiesel equipment was the most feasible resource combination under the randomly generated populations. Similarly, the results for Case Study 2 output HIP mix with biodiesel equipment as the most feasible solution. HIP mix is the best performing material under 
extreme conditions. The original project utilized Superpave as the asphalt type. The main reasons for not using HIP in the original project were the specific requests of FDOT as well as the unavailability of HIP equipment as it was a new technology. However, HIP technology has been evaluated effective in saving about 50\% cost over the conventional milling and resurfacing, and eliminated $90 \%$ of the emissions resulting from pavement milling and resurfacing process. Additionally, HIP showed reduced downtime of pavements being restored in recent projects (EPA, 2016). Thus, the optimal solution not only was practical and reliable, but also resulted in better resource utilization plans in achieving environmentally conscious construction.

In the last step, the Pearson's correlation was used to find out the relationship of TCEI related to the project conditions by using the random population of solutions created before. The correlation coefficient was calculated for time and EI, and cost and EI. The correlation coefficients of TCEI for Case Study 1 and Case Study 2 are shown in Table 8 and Table 9.

\section{Table 8 Correlation Coefficients of TCEI for Case Study 1}

\section{Table 9 Correlation Coefficients of TCEI for Case Study 2}

The value of the correlation coefficient defines two properties of the correlation: (1) The sign of $r$ shows if the correlation is negative or positive; (2) The magnitude of $r$ indicates the strength of correlation. Between time and cost, $r=0.9466$ and 0.8497 suggests a strong positive correlation. When the correlation coefficient is between 0.3 and 0.7 as in the case of cost and EI, it is interpreted as a moderate positive correlation. Between time and EI, the correlation coefficient is below 0.3 , which suggests a weak positive correlation. 
While the correlation coefficient (r) indicates the existence of relationship between two variables, the coefficient of determination $\left(\mathrm{r}^{2}\right)$ represents the proportion of common variation in the two variables. For example, for Case Study 1, the coefficient of determination $\left(\mathrm{r}^{2}\right)$ of 0.90 between time and cost suggests that $90 \%$ of the variability in the cost of the project is explained by its duration. Similarly, the coefficient of determination of 0.23 between GHG and cost suggests that $23 \%$ of the variability in the cost of the project is explained by its GHG, and the coefficient of determination of 0.04 between time and GHG suggests that only $4 \%$ of the variability in the GHG of the project is explained by its duration. For Case Study 2, the coefficient of determination between time and cost is $72 \%$, between GHG and cost is $24 \%$, and between time and GHG is 5\%. On average, the coefficient of determination between time and cost is $81 \%$, between GHG and cost is $23.5 \%$, and between time and GHG is $4.5 \%$.

The optimization model was numerically verified by using constraints for T, C, and EI. The constraint of $\mathrm{T}$ was defined as $\mathrm{T}_{0^{-}}$a predefined project deadline, while the constraint of $\mathrm{C}$ was defined as $\mathrm{C}_{0^{-}}$a predefined maximum project budget. Three objective functions were used in verification as given in Table 10. The results showed that the most feasible T, C, EI combination selected stays below the pre-defined constraints for both case studies. As multiobjective optimization was performed with the objective of minimizing project duration, project cost and project GHG, the optimal solution selected (e.g. using HIP mix with biodiesel equipment) was the most feasible resource combination under the randomly generated probabilities. The optimal solution was practical and reliable, as HIP mix presented considerable performance in time, cost and GHG objectives of construction projects. Considering the results, the proposed approach derived reliable results in optimizing TCEI. 


\section{Table 10 Objective Functions vs Constraints for Verification of the Model}

\section{Conclusions and Recommendations}

The construction industry has considerable impact on resource consumption and environmental impact. Although, environmentally conscious construction has been widely studied, existing literature is still in need of a multi-objective perspective. An LCA-based multi-objective optimization procedure is presented in this paper to partially fulfill this need.

The results of multi-objective optimization showed that using HIP mix with biodiesel equipment was the most feasible resource combination under the randomly generated probabilities, i.e., it was the optimal solution considering time, cost and GHG emissions. It was not selected originally for some projects for being a slightly new technology that requires specific equipment. Additionally, the contractors were not familiar with the technology. However, the optimal results show the success in all three project parameters (TCEI), which makes it inevitably for the HIP technology to spread quickly. Nevertheless, the optimal solution was practical and reliable, as HIP mix presented considerable performance in time, cost and GHG objectives of construction projects. Considering the results, the proposed framework yielded statistically significant results in optimizing TCEI.

The multi-objective optimization procedure in this study resulted in remarkable outputs regarding the interdependency between TCEI. Pearson's correlation was used to determine the extent of relationship between the three project objectives. The correlation coefficient (r) and the coefficient of determination $\left(\mathrm{r}^{2}\right)$ helped to visualize the TCEI interdependency based on different 
construction operations, where alternative ways of performing the same operations have been considered.

First, the coefficient of determination of 0.81 between time and cost suggests that there is a positive relationship between the project cost and project duration. This is something that can be observed from the data set. The reason for $81 \%$ being different from generally accepted timecost tradeoff lies beneath the construction methods. The new technology in delivering various construction activities causes a decrease in both time and cost, so that they have a common variation. Additionally, switching fuel types or equipment types not only affects GHG emissions, but also shows the same kind of behavior for time and cost. This situation of having the same increase or decrease of time and cost shows consistency in their pattern.

Secondly, the coefficient of determination of 0.235 between GHG emissions and cost suggests that $23.5 \%$ of the variability in the cost of the project is explained by its GHG emissions. The common variation between GHG and cost is low, as the GHG data do not always increase when cost increases.

Finally, the coefficient of determination of 0.045 between time and GHG emissions suggests that only $4.5 \%$ of the variability in the GHG emissions of the project is explained by its duration. The very low variability can be explained by the data set, as the data of time \& GHG does not show the same pattern of behavior. The duration of project based on different construction methods can have the same value, while having the same GHG value is only limited to certain construction methods.

The correlation coefficient has suggested positive correlation between the three objectives. However, the strength of correlation between objectives is different. Time and cost have strong correlation, while cost and GHG emissions have moderate correlation. The weakest 
correlation has been found between time and GHG emissions. As GHG emissions and cost or time and GHG emissions do not have a strong correlation, the relationships between them are in general case-by-case. For each case, the variability between each pair can change. Therefore, whether or not there is a certain relationship between these objectives cannot be generically set.

One of the major challenges of the study is related to data availability. The challenges apply to both quantitative and qualitative data collection and processing. In terms of quantitative data, time, cost and environmental impact data are needed for all construction operation alternatives, besides the construction operation method that is applied. For the applied construction operation method, the unit costs and quantities of resources, as well as schedules are available for calculating time and cost. For other alternatives, time and cost can be estimated by using conventional methods. On the other hand, the environmental impact data for actual construction operation are difficult to acquire, because of the lack of LCI data. Additionally, it is a challenge to address the uniqueness of different projects without proper highway LCA software. This research required the derivation of a LCI specific to highway construction to overcome these issues.

In the future, the current LCI database can be extended to include a collaborative platform where the project parties (e.g. owner, contractor, vendors, etc.) can share information regarding construction operations. Having such an online platform will enable more accurate data collection and ease LCA process. It should also be noted that the environmental impact in this research was limited to GHG emissions because of the availability of data. However, the proposed optimization can be applied to include other impact categories to examine the effect of construction operations from a life cycle point of view. 


\section{Acknowledgements}

The authors gratefully acknowledge the financial support provided by the National Science Foundation (NSF) under the NSF award No. \#1000136. The views and opinions expressed in this paper are those of the authors and do not necessarily reflect the views and opinions of the National Science Foundation.

The authors also thank the FDOT for sharing their insight and expertise that greatly assisted the research effort.

\section{References}

ATHENA. (2016). Athena Pavement LCA/Athena Sustainable Materials Institute (SMI). Retrieved April 2016, from http://www.athenasmi.org/our-software-data/impactestimator-for-highways/

Bahia, H. U. (1993). Bibliographies for physical properties of asphalt cement, SHRP-A-626. Washington, DC.: National Research Council.

Bengtsson, M. (2001). Weighting in practice: implications for the use of life-cycle assessment in decision making. Journal of Industrial Ecology, 4(4), 47-60.

Bilec, M., Ries, R., Matthews, H. S., \& Sharrard, A. L. (2006). Example of a hybrid life cycle assessment of construction processes. Journal Infrastructure Systems, 12, 207-215.

Bushman, W., Freeman, T., \& Hoppe, E. (2004). Stabilization Techniques for Unpaved Roads. Charlottesville, VA: Virginia Transportation Research Council.

Carpenter, A., Gardner, K., Fopiano, J., Benson, C., \& Edil, T. (2007). Life Cycle Based Risk Assessment of Recycled Materials in Roadway Construction. Waste Management, 27, 1458-1464.

CCE. (2005). Road Rehabilitation Energy Reduction Guide for Canadian Road Builders. Canadian Construction Association . Ontario: Natural Resources Canada.

Chehovits, J., \& Galehouse, L. (2010). Energy Usage and Greenhouse Gas Emissions of Pavement Preservation Processes for Asphalt Concrete Pavements. First International Conference on Pavement Preservation, (pp. 27-42). Newport Beach, CA. 
Chowdhury, A., \& Button, J. W. (2008). A Review of Warm Mix Asphalt. Texas A\&M University System, Texas Transportation Institute, College Station, TX.

El-Rayes, K., \& Kandil, A. (2005). Time-cost-quality trade off analysis for highway construction. Journal of Construction Engineering and Management, 131(4), 477-486.

EPA. (2003). User's guide to MOBILE 6.1 and MOBILE 6.2: mobiles source emission factor model. Washington, D.C.: U.S. Environmental Protection Agency.

EPA. (2009). Potential for Reducing Greenhouse Gas Emissions in the Construction Sector. U.S. Environmental Protection Agency, Washington, DC.

EPA. (2016). Evaluation of the 100\% Recyclability of Superpave Hot Mix Asphalt. Retrieved April 2016, from Extramural Research: http://cfpub.epa.gov/ncer_abstracts/INDEX.cfm/fuseaction/display.abstractDetail/abstract 19497/report/0

Feng, C., Liu, L., \& Burns, S. (1997). Using genetic algorithms to solve construction time-cost trade-off problems. Journal of Computing in Civil Engineering, 11(3), 184-189.

Gambatese, J. (2005). Sustainable Roadway Construction: Energy Consumption and Material Waste Generation of Roadways. Construction Research Congress (p. 183). San Diego, CA: Construction Institute (CI).

Griego, D., Krarti, M., \& Heranandez-Guerrero, A. (2015). Energy efficiency optimization of new and existing office buildings in Guanajuato, Mexico. Sustainable Cities and Society, $17,132-140$.

Hassan, M. M. (2009). Life-Cycle Assessment of Warm-Mix Asphalt: An Environmental and Economic Perspective. The 88th Transportation Research Board Annual Meeting. Washington, DC.

Huddleston, J. (2008). Sustainable Pavement Management Practices. Northwest Pavement Management Association 2008 Fall Conference. Vancouver, WA.

ISI. (2016). Institute for Sustainable Infrastructure (ISI). Retrieved April 1, 2016, from Envision ${ }^{\mathrm{TM}}$ Sustainability Rating System: http://sustainableinfrastructure.org/envision/

Jha, M., Shariat, S., Abdullah, J., \& Devkota, B. (2012). Maximizing Resource Effectiveness of Highway Infrastructure Maintanence Inspection and Scheduling for Efficient City Logistics Operations. Procedia-Social and Behavioral Sciences, 39, 831-844.

Kibert, C. (2002). Policy Instruments for a Sustainable Built Environment. Journal of Land Use and Environmental Law, 17, 379-394. 
Kua, H. W., \& Lee, S. E. (2002). Demonstration intelligent building-a methodology for the promotion of total sustainability in the built environment. Building and Environment, 37, 231-240.

Larsen, D. A. (2003). Demonstration and Evaluation of SUPERPAVE Technologies, Final Evaluation Report for CT Route 2, Report No: 2219-F-02-7. Connecticut Department of Transportation, Bureau of Engineering and Highway Operations Research and Materials, Rocky Hill, CT.

Li, X., Zhu, Y., \& Zhang, Z. (2010). An LCA-based environmental impact assessment model for construction processes. Building and Environment, 45(3), 766-775.

Marzouk, M., \& Moselhi, O. (2004). Multiobjective optimization of earthmoving operations. Journal of Construction Engineering and Management, 130(1), 105-113.

Marzouk, M., Madany, M., Abou-Zied, A., \& El-Said, M. (2008). Handling construction pollutions using multi-objective optimization. Construction Management and Economics, $26,1113-1125$.

NREL. (2004). U.S. LCI Database Project: User Guide. Golden, CO: The National Renewable Energy Laboratory.

Ozcan-Deniz, G. (2011). An integrated multi-agent framework for optimizing time, cost and environmental impact of construction processes. FIU. Miami, FL: ProQuest ETD Collection for FIU.

Ozcan-Deniz, G., \& Zhu, Y. (2016). A Multi-Objective Decision-Support Model for Selecting Environmentaly Concious Highway Construction Methods. Journal of Civil Engineering and Management, 21(6), 733-747.

Russell, M., Uhlmeyer, J. S., DeVol, J., \& Johnson, C. (2010). Evaluation of Hot In-Place Recycle. Washington State Department of Transportation, Materials Laboratory, MS47365, Olympia, WA.

Sartori, I., \& Hestnes, A. G. (2007). Energy use in the life cycle of conventional and low-energy buildings: A review article. Energy and Buildings, 39, 249-257.

Stern, N., Peters, S., Bakhshi, V., Bowen, A., Cameron, C., Catovsky, S., . . Stock, M. (2006). Stern Review: The Economics of Climate Change. London: HM Treasury.

Terrel, R. L., \& Hicks, R. G. (2008). Viability of Hot In-Place Recycling as a Pavement Preservation Strategy. California Pavement Preservation Center, CP2 Center, Chico, CA. 
Tronchin, L., Manfren, M., \& Tagliabue, L. (2015). Optimization of building energy performance by means of multi-scale analysis - Lessons learned from case studies. Sustainable Cities and Society, In Press.

Truitt, P. (2009). Potential for reducing greenhouse gas emissions in construction sector. EPA Sector Strategies Program. Washington, D.C.: U.S. EPA .

Uhlman, B. (2009). Principals of Eco-Efficiency Analysis in Construction Applications. Palm Springs, CA: ARRA-AEMA-ISSA Annual Meeting.

USGBC. (2008). A National Green Building Research Agenda. (the U.S. Green Building Council (USGBC) Research Committee) Retrieved April 2016, from http://www.usgbc.org/sites/default/files/Docs3402.pdf

USGBC. (2012). Green Building and LEED Core Concepts Guide (2nd ed.). Washington, DC: U.S. Green Building Council.

USGS. (2006). Materials in Use in U.S. Interstate Highways. US Geological Survey Fact Sheet 2006-3127. US Department of the Interior.

Varun, Sharma, A., Shree, V., \& Nautiyal, H. (2012). Life cycle environmental assessment of an educational building in Northern India: A case study. Sustainable Cities and Society, 4, $22-28$.

Yao, H., Shen, L. Y., \& Yam, C. M. (2007). A fuzzy-analysis-based method for measuring contractor's environmental performance. Management of Environmental Quality: An International Journal, 18(4), 442-458.

Zheng, D. X., Ng, S. T., \& Kumaraswamy, M. M. (2005). Applying Pareto Ranking and Niche Formation to Genetic Algorithm-Based Multiobjective Time-Cost Optimization. Journal of Construction Engineering and Management, 131(1), 81-91. 
Table 1 Construction Methods for Resurfacing Project Activities

\begin{tabular}{|l|l|l|}
\hline \multicolumn{3}{|c|}{ Construction Methods } \\
\hline Resurfacing & Milling & Friction Course \\
\hline Virgin-Conventional HMA & Conventional equipment & FC-5 \\
\hline Virgin-Conventional HMA & Biodiesel equipment & FC-5 \\
\hline Recycled-Conventional HMA & Conventional equipment & FC-5 \\
\hline Recycled-Conventional HMA & Biodiesel equipment & FC-5 \\
\hline Virgin-WMA & Conventional equipment & FC-5 \\
\hline Superpave & Conventional equipment & FC-5 \\
\hline HIP Mix (Marshall+milled) & HIP's equipment & FC-5 \\
\hline HIP Mix (Marshall+milled) & HIP Biodiesel & FC-5 \\
\hline Virgin-Conventional HMA & Conventional equipment & FC-9,5 \\
\hline Virgin-Conventional HMA & Biodiesel equipment & FC-9,5 \\
\hline Recycled-Conventional HMA & Conventional equipment & FC-9,5 \\
\hline Recycled-Conventional HMA & Biodiesel equipment & FC-9,5 \\
\hline Virgin-WMA & Conventional equipment & FC-9,5 \\
\hline Superpave & Conventional equipment & FC-9,5 \\
\hline HIP Mix (Marshall+milled) & HIP's equipment & FC-9,5 \\
\hline HIP Mix (Marshall+milled) & HIP Biodiesel & FC-9,5 \\
\hline
\end{tabular}

Table 2 Gas Releases for Gasoline Equipment (source: EPA single truck)

\begin{tabular}{ll}
\hline Type of Gas & Release Amount $(\mathbf{k g} / \mathbf{L})$ \\
\hline Carbon dioxide (CO2) & $2.27 \mathrm{E}+00$ \\
Carbon monoxide (CO) & $4.07 \mathrm{E}-02$ \\
Methane (CH4) & $4.89 \mathrm{E}-04$ \\
Nitrogen oxides (NOx) & $1.33 \mathrm{E}-02$ \\
Nitrous oxide (N2O) & $9.56 \mathrm{E}-05$ \\
Particulates, > 2.5 um, and < 10um & $6.50 \mathrm{E}-05$ \\
Sulfur oxides (SOx) & $5.42 \mathrm{E}-04$ \\
VOC, volatile organic compounds & $3.03 \mathrm{E}-03$ \\
\hline
\end{tabular}

Table 3 Gas Releases for Diesel Equipment (source: EPA single truck)

\begin{tabular}{ll}
\hline Type of Gas & Release Amount $\mathbf{( k g / L )}$ \\
\hline Carbon dioxide (CO2) & $2.93 \mathrm{E}+00$ \\
Carbon monoxide $(\mathrm{CO})$ & $4.21 \mathrm{E}-03$ \\
Methane $(\mathrm{CH} 4)$ & $7.07 \mathrm{E}-05$ \\
Nitrogen oxides (NOx) & $2.09 \mathrm{E}-02$ \\
Nitrous oxide (N2O) & $1.06 \mathrm{E}-04$ \\
\hline
\end{tabular}


Table 5 A Random Population of TCEI Results from Case Study 1

\begin{tabular}{cccc}
\hline Trial \# & T & C & GHG \\
\hline 1 & 36 & $\$ 1,945,751.89$ & $3,857,983.11$ \\
2 & 36 & $\$ 1,945,751.89$ & $3,857,983.11$ \\
3 & 36 & $\$ 1,998,046.87$ & $4,130,521.55$ \\
4 & 36 & $\$ 1,830,894.80$ & $2,704,097.84$ \\
5 & 36 & $\$ 1,830,894.80$ & $2,704,097.84$ \\
6 & 36 & $\$ 1,832,741.60$ & $2,704,097.84$ \\
7 & 36 & $\$ 1,961,275.87$ & $4,556,064.96$ \\
8 & 36 & $\$ 1,832,741.60$ & $2,704,097.84$ \\
9 & 36 & $\$ 1,832,741.60$ & $2,704,097.84$ \\
10 & 36 & $\$ 1,363,662.60$ & $3,857,983.11$ \\
11 & 22 & $\$ 1,363,662.60$ & $3,313,032.61$ \\
12 & 22 & $\$ 1,961,275.87$ & $3,313,032.61$ \\
13 & 36 & $\$ 2,026,281.78$ & $4,556,064.96$ \\
14 & 36 & $\$ 2,026,281.78$ & $4,466,841.63$ \\
15 & 36 & $\$ 1,832,741.60$ & $4,466,841.63$ \\
16 & 36 & $\$ 1,945,751.89$ & $2,704,097.84$ \\
17 & 36 & $\$ 1,961,275.87$ & $3,857,983.11$ \\
18 & 36 & $\$ 2,026,281.78$ & $4,556,064.96$ \\
19 & 36 & $\$ 1,363,662.60$ & $4,466,841.63$ \\
20 & 22 & & $3,313,032.61$ \\
\hline
\end{tabular}


Table 6 A Random Population of TCEI Results from Case Study 2

\begin{tabular}{cccc}
\hline Trial \# & T & C & GHG \\
\hline 1 & 108 & $\$ 4,047,989.76$ & $6,956,337.59$ \\
2 & 108 & $\$ 4,582,856.76$ & $6,956,337.59$ \\
3 & 195 & $\$ 6,061,772.88$ & $11,193,067.86$ \\
4 & 195 & $\$ 6,068,600.57$ & $9,308,047.82$ \\
5 & 195 & $\$ 5,570,104.61$ & $7,190,512.66$ \\
6 & 195 & $\$ 5,576,932.31$ & $5,305,492.62$ \\
7 & 195 & $\$ 6,255,120.27$ & $10,974,117.91$ \\
8 & 195 & $\$ 5,766,987.62$ & $8,186,146.27$ \\
9 & 108 & $\$ 4,576,299.03$ & $8,483,343.00$ \\
10 & 108 & $\$ 4,582,856.76$ & $6,956,337.59$ \\
11 & 195 & $\$ 5,526,905.88$ & $11,134,176.56$ \\
12 & 195 & $\$ 5,533,733.57$ & $9,308,047.82$ \\
13 & 195 & $\$ 5,035,237.61$ & $7,131,621.36$ \\
14 & 195 & $\$ 5,042,065.31$ & $5,305,492.62$ \\
15 & 195 & $\$ 5,720,253.27$ & $10,915,226.61$ \\
16 & 195 & $\$ 5,232,120.62$ & $8,186,146.27$ \\
17 & 108 & $\$ 4,041,432.03$ & $8,424,451.70$ \\
18 & 108 & $\$ 4,047,989.76$ & $6,956,337.59$ \\
19 & 195 & $\$ 5,576,932.31$ & $5,305,492.62$ \\
20 & 195 & $\$ 5,035,237.61$ & $7,131,621.36$ \\
\hline
\end{tabular}

Table 7 Fitness Function Values and Normalized TCEI (Case Study 1)

\begin{tabular}{ccccc}
\hline Trial \# & Normal C & Normal T & Normal GHG & Fitness \\
\hline 1 & 0.88 & 1.00 & 0.62 & 1.47 \\
2 & 0.88 & 1.00 & 0.62 & 1.47 \\
3 & 0.96 & 1.00 & 0.77 & 1.58 \\
4 & 0.71 & 1.00 & 0.00 & 1.22 \\
5 & 0.71 & 1.00 & 0.00 & 1.22 \\
6 & 0.71 & 1.00 & 0.00 & 1.23 \\
7 & 0.90 & 1.00 & 1.00 & 1.68 \\
8 & 0.71 & 1.00 & 0.00 & 1.23 \\
9 & 0.71 & 1.00 & 0.00 & 1.23 \\
10 & 0.88 & 1.00 & 0.62 & 1.47 \\
11 & 0.00 & 0.00 & 0.33 & 0.33 \\
12 & 0.00 & 0.00 & 0.33 & 0.33 \\
13 & 0.90 & 1.00 & 1.00 & 1.68 \\
14 & 1.00 & 1.00 & 0.95 & 1.70 \\
\hline
\end{tabular}




\section{Table 8 Correlation Coefficients of TCEI for Case Study 1}

\begin{tabular}{cccc}
\hline & $\mathrm{C}$ & $\mathrm{T}$ & $\mathrm{EI}$ \\
\hline $\mathrm{C}$ & 1 & & \\
$\mathrm{~T}$ & 0.9466 & 1 & \\
$\mathrm{EI}$ & 0.4789 & 0.1887 & 1 \\
\hline
\end{tabular}

Table 9 Correlation Coefficients of TCEI for Case Study 2

\begin{tabular}{cccc}
\hline & $\mathrm{C}$ & $\mathrm{T}$ & $\mathrm{EI}$ \\
\hline $\mathrm{C}$ & 1 & & \\
$\mathrm{~T}$ & 0.8497 & 1 & \\
$\mathrm{EI}$ & 0.4910 & 0.2245 & 1 \\
\hline
\end{tabular}

Table 10 Objective Functions vs Constraints for Verification of the Model

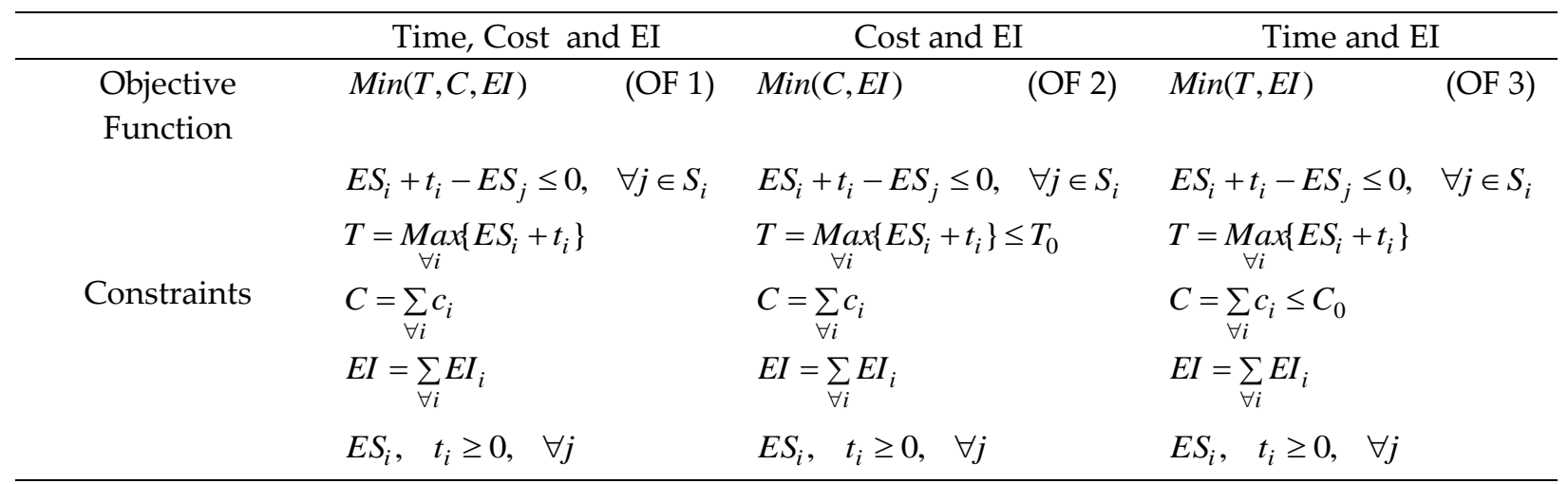

Notes: T-time; C-cost; EI-results of life cycle assessment; $E S_{i_{-}}$early start of activity $i_{i} t_{i}$ - duration of activity $i$; $S_{i}$ successor activity set of activity $i$; ${ }^{i_{i}}$-cost of activity $i$; $E I_{i}$ - life cycle assessment of activity $i$; $T_{0}$ - a predefined project deadline; $C_{0}$ - a predefined maximum project budget. 